\title{
Augmented Reality Internet Labs versus its Traditional and Virtual Equivalence
}

\author{
http://dx.doi.org/10.3991/ijet.v10i3.4354 \\ Salaheddin Odeh $^{1}$, Shatha Abu Shanab ${ }^{2}$, Mahasen Anabtawi ${ }^{1}$ \\ ${ }^{1}$ Al-Quds University, Abu Dies, Jerusalem, Palestine. \\ ${ }^{2}$ Palestine Technical University-Kadoori, Tulkarm, Palestine.
}

\begin{abstract}
Engineering is an applied science; it makes science come alive through experiments and labs. Students can only gain practical knowledge that goes beyond mere scientific theory in the educational labs. This can be done using three different types of educational labs: Augmented reality labs, Virtual labs and Traditional labs. It is crucial to pre-specify the learning objectives associated with each experiment in order to be able to meet them no matter what the method of delivery is. This paper focuses on an empirical study that compares the three types of labs after specifying the associated learning objectives.
\end{abstract}

Index Terms-Remote Lab, Augmented Reality, Comparative Evaluation, Virtual Lab, Traditional Lab, Learning Objectives.

\section{INTRODUCTION}

It is undeniable that labs present an essential part in engineering education because they provide practical knowledge for students. Traditional labs are available for little and limited periods for a huge number of students. The major disadvantage for this type of labs refers to costly equipment and instruments required; an approach to bypass the mentioned problems is by employing virtual and remote labs that assist students in developing their practical skills. However, applying this type of labs leads to the fact that students suffer from the weakness of reality representation of experiment equipment [1].

Augmented reality is defined as the combination of real environment with virtual computerized objects such as text, 2D images, or 3D models, and/or enhancement to sound, graphics or other human senses. Both the visualization of the application presented through a user-interface to the user or the appearance of user in this ultimate system samples as she/he is working in a single real environment [1].

A developed system will be briefly introduced that improves performing experimental lab through Internet using augmented reality technique. Building this system is of great significance as a prototype is necessary to evaluate carrying out experiments through conventional and AR remote labs. To achieve the previously mentioned objective, the applications of AR technologies in other fields were studied. Understanding the ideas and the techniques behind such applications might be helpful for contributing of newer ideas to our remote AR lab. Furthermore, in order to categorize our approach in the remote labs' landscape, it is significant to be familiar with other kinds of remote labs as well as e-learning located behind these techniques. The AR user-interface of the developed remote lab, which will be fed with picture data of the physical experiment on the server side, represents one of the major concerns of this research. The student interacts with the remote system through the interaction devices: mouse, keyboard and monitor. At the begin of an experiment session, she/he has to establish a connection to the remote located AR lab, offering a real view of experiment's circuit by adding an overlapping image or text on the delivered Webcam picture of kit. Once the connection is established, the student can begin to manipulate the experiment.

In this paper we will focus on the evaluation of the AR remote lab whose visualization uses a form of mixed virtual and real (video-captured) lab elements that can not only be simple elements such as resistors, capacitors, inductors, but also more complicated units such as oscilloscopes, DDMs, function generators as well. This evaluation compares our AR remote lab with other two lab approaches: traditional and virtual labs in order to find out how much effective AR Internet labs assist students in understanding and reinforcing their theoretical concepts according to the pre-specified learning objectives.

\section{ROLE OF LABS IN ENGINEERING EDUCATION}

Emphasis on labs has varied over the years. Prior to the creation of engineering schools, engineering was taught in an apprentice ship, which means that their knowledge and ability to design, analyze and build their own systems was gained from practice and labs. During the middle of the nineteenth century, during the industrial revolution, engineering schools were established, their curricula had a heavy emphasis on labs; labs were a major part of the engineering education during that era.

In 1932, the Engineers' Council for Professional Development (ECPD) was established. It's the forerunner of the ABET [2]. ECPD criteria for accreditation of engineering included students, curricula, physical facilities and graduates; but the labs were not. This can be explained by the fact that labs were so central to an engineering degree, that no one could ever consider teaching an engineering course without an accompanying lab [3]. After World War II, most inventions were developed by scientists rather than engineers. A committee was formed to recommend the suitable pattern of engineering education needed to cope with the rapid changes in science. Unfortunately, this committee wrote a report called Grinter report after its chairman, which stated that: "Engineers are too practically oriented, and must be trained more to learn the basic sciences and theories".

By the 1970s, number of students enrolled in engineering schools reduced dramatically. In order to save losses, 
many engineering schools minimized their laboratory courses citing the Grinter report's conclusion. In 1980, a major change occurred to engineering education, as ECPD turned into Accreditation Board for Engineering and Technology (ABET). ABET undertook a study on how to better accredit engineering programs. It demanded that each institution develop its goals and objectives for its programs to develop outcomes that could be periodically assessed [4]. ABET declared that clear objectives are essential in designing an efficient learning system.

For laboratory courses, common goals are: relating theory and practice, bringing real world into labs, providing motivation to continue in the study of engineering, and following a particular course of study [5], [6], [7], [8], [9]. Common assessment examples of laboratory courses include: student retention, student satisfaction survey, and efficacy of learning simulations used as a pre-lab activity [10].

ABET and Sloan Foundation agreed to fund a colloquy on January 2002, in which 50 engineering educators attended. The colloquy converged on a list of 13 fundamental objectives categorized into three main areas, which are:

1. The category dealing with cognition, which includes five objectives, namely, instrumentation, models, experiment, data analysis and design.

2. The category dealing with psychomotor, which means the ability to manipulate apparatus and includes two objectives: psychomotor and sensory awareness.

3. The category having cognitive and affective domain, which includes the following six objectives, namely, learn from failure, creativity, safety, communication, teamwork and ethics in the lab [11], [12].

\section{E-LEARNING AND DiSTANCE EDUCATION}

The usual approach that universities applied to solve the problem of attending labs in the distance education is to either have students perform e-lab exercises at other institutions or spend period of time on the engineering campus in a concentrated lab course [13]. Other universities gave students remote lab kits to perform experiments at home [14]. The distance education programs then adopted every new technology as it came along, as mail, telephone, radio, television and computers. Then, Internet came, and was able to provide education for students at "any time, in any place". Using Internet made it possible to save efficiencies by better utilizing space and making a single piece of lab equipment available to more students. Internet can be used to provide students with remote access to physical lab apparatus. It can be used to either give students access to physical equipment in a physical lab, or give students access to simulation. Students access to experimental apparatus is through a computer terminal; so the big two questions are whether these two options will make a difference to the student. Another alternative is that whether we need to care what the students perceive as long as the learning objectives associated with the lab are met. In other words, do we have to concentrate on the fundamental objectives of labs independent of the method of delivery?

\section{Traditional, Virtual LabS AND REMOte LABS}

The main purpose of engineering education is to prepare engineers who can deal with equipment and instruments. Since engineering is an applied science, its courses are containing the biggest part of lab studies. Therefore, labs are essential in scientific education. Recently, the environments of labs have been changed by e-learning technologies, which have opened many doors in education. Students learn more efficiently if they have the chance to carry out experiments because they allow students to compare theories with experiments, collaborate with each other, and give them chance to follow their interests. Unfortunately, many engineering courses do not contain lab component because of great expense and space considerations. Different technologies offer new ways of many educational objectives that changed the lab education land [15]. By using text, pictures and illustrations, and multimedia, we can build simulations of complex processes of biological and medical sciences, agriculture, engineering and educational practice, which are not easily accessible in real time and settings. Simulations allow a student not only to see what is complex, but he can learn from hands on experience as well [16]. In a hands-on lab, a real experiment is locally realized. Two characteristics differentiate hands-on from the other two labs [17]. On the one hand, the real equipment that is used in the lab is physically locally connected, and on the other, the students and the equipment must locally present in the same land of lab.

In the last decades, the usage of virtual labs or simulation lab has increased rapidly in engineering education. Virtual labs enable the student to access the engineering applications easily at anytime and from any computer. Examples of these engineering applications are simulations, demonstrations, and exercises. A virtual lab is a software simulation, which is an imitation of a real experiment represented by a mathematical model. In other words, virtual labs imitate the hand-on lab; that is, instead of performing the experiment on actual equipment, the tests and possibly even the data are simulated on a computer [18]. Unfortunately, this weakens students' reference to reality, and thus, they cannot later deal with these components and instruments in real work. Where a simulation commonly replaces the real system, virtual labs typically resort to simulation software such as MATLAB or LabVIEW or specific applications.

Remote labs benefit from contemporary e-leaning and Internet technologies. Now, many academic institutions provide a variety of remote labs experimentations designated as Web-based labs or online labs; these labs support remotely controlled physical experiments [19]. Remote lab may be defined as a lab accessed via a communication network in order to execute a lab experiment, whose usage involves real devices and equipment. The lab server communicates between the user and the physical experiment in the lab [20]. This type of lab is suitable to distance learning courses where students do not need to be locally present on campus. The instruments of an experiment that is controlled through personal computer, is the core of the remote lab. These instruments can be remotely configured by software that makes it easily to share of expensive instruments and equipment. A remote lab must be provided with an interface to send commands and receive feedback from the lab equipment. There are a number of methods that provide remote access to the lab equipment. The general method is the use of a Web browser such as Internet Explorer and Firefox. User access is regulated by schedule and limited time. 


\section{SOME HARDWARE/SOFTWARE ASPECTS OF THE DEVELOPED AR REMOTE LAB}

In order to compare a remote lab using augmented reality with hands-on and virtual labs, it was necessary to specify, design and implement a new one. The experiment used is already available as hands-on. The corresponding virtual lab consisting of a simulation experiment can be created with any simulation software such as MATLAB or LabVIEW or specific applications that is known as problem solving environment (PSE). This approach employs programming code to simulate the result of engineering or scientific problems using quite sophisticated numerical analysis, programming, and graphical tools. Best known of these PSEs is MATLAB, Pspice etc. An augmented reality remote lab is a system composed of hardware and software components that involve the ability to access physical labs through Internet. Individual students utilize a communication network to perform a lab experiment, and interact with a Webpage to access the lab from their homes independent from time and place. In following, we will briefly describe the AR remote lab developed in this research to study how much AR is appropriate to visualize remote labs, describing its distributed system architecture. The main circuit is displayed on student's computer screen with all required components and instruments for enabling him to operate on his experiment interactively. The circuit is consisting of ten red light emitter diodes that are connected in series with each other; these LEDs are located at the terminals of each component and instrument to be wired. The LEDs circuit is necessary in order to assist the HSL filter, which is implemented in forms of a software program, to determine the positions of node's components and instruments on the captured video photo of the AR remote lab's kit.

For allowing effective human-computer interaction, user-centered socio-technical systems must consist not only of pure technical software and hardware components, but demand well designed graphics promoted through taking various ergonomic aspects into account [21]. The userinterface plays a central role for obtaining a harmonic interaction with the whole lab, obligating the necessity to create it with an interactive development environment supporting prototyping and evolutionary development [22] such as the Microsoft dot Net environment, which offers an integrated environment with powerful user-interface tools and rich libraries for creating user-interface components to enable data to be displayed in many forms.

As Fig. 1 shows, the representation of the experiment components such resistors and transistors etc. as well as the used instruments are real using real-time video pictures [23]. As a result, the experimenting student deals with the reality and not with a simulated world, e.g. she/he sees real resistors and instruments and, therefore, she/he can read its value by either using the color rings on the resistors, or calculating resistor values through displayed voltages and currents of these resistors. In this research, wiring of the real represented experiment circuit will be performed based on the AR, where, as previously mentioned, real video pictures are overlapped with virtual wires. The experimenting kit of the AR remote lab visualized on the client user-interface contains all required components and instruments. Using the interaction devices mouse and keyboard, the student can wire his experimental circuit using the last picture taken; this step leads to reduce the distortion of the transferred image that depends on the bandwidth of the Internet. A connection between two nodes on

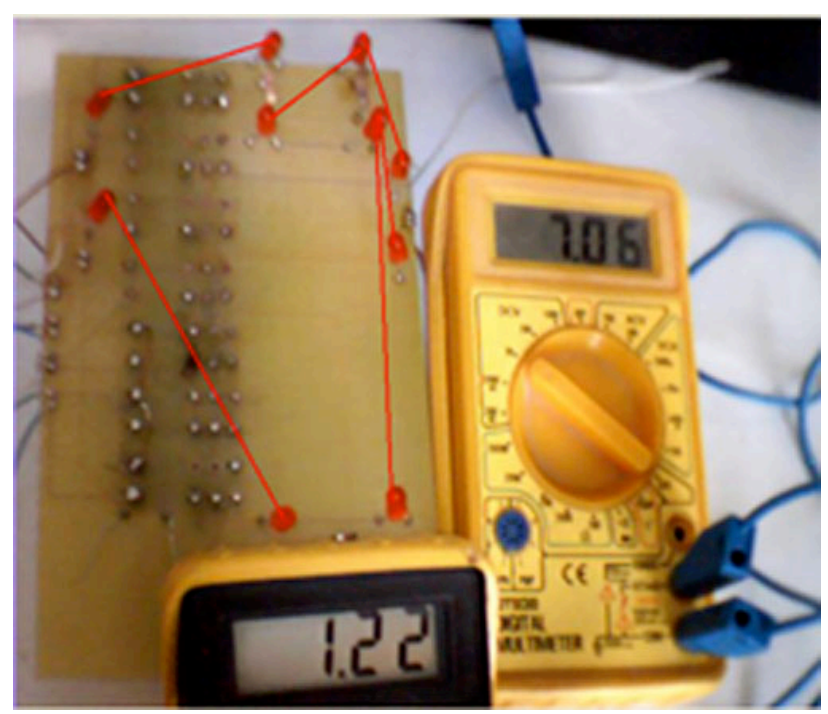

Figure 1. A virtually wired real circuit in the AR remote lab leads to AR based visualization.

the circuit board is implemented by clicking on the first node and then clicking on the second node, causing that a line between them is drawn (see Fig. 1). So when the student wire point one $(\mathrm{x} 1, \mathrm{y} 1)$ with point two $(\mathrm{x} 2, \mathrm{y} 2)$, the software take the $(\mathrm{x}, \mathrm{y})$ coordinates of these points (pixels) and refer for node matrix, then take the entries $\mathrm{N}(\mathrm{x} 1$, $y 1)$ that present the node's number of first clicked node and $\mathrm{N}(\mathrm{x} 2, \mathrm{y} 2)$ that present the node's number of second clicked node, put these two elements as a row in matrix, when the student start wiring second wire previous steps again time and put the taken nod's numbers from node matrix in new row and so on.

\section{COMPARATIVE EVALUATION}

One of our objectives of this research study is to find out how much effective augmented reality Internet labs assist students in understanding and reinforcing their theoretical concepts. Swan and Gabbard carried out a survey study showing that between 1998 and 2004, less than $10 \%$ of a representative sample of AR scientific publications reported studies with real users [24]. As an example is an evaluation to find out limitations of usability issues of an augmented reality environment dedicated for design [25]. An obvious way for doing that would be a comparative evaluation, which compares our system, the AR remote lab, with traditional and virtual labs. Evaluation of new practical educational systems depends on student surveys to measure the achievement of the required practical skills of the students from these categories of labs, compared with other traditional ones.

A survey questionnaire of closed end questions was implemented and the raw data was collected in order to investigate student perceptions of their experiences of handon, virtual, and augmented reality labs in this case study. Closed-end questions are questions in which all possible answers are identified, and the respondent is asked to choose one of the answers (Strongly disagreement, Disagreement, Neutral, Agreement, Strongly disagreement). According to Reja et al. [26], closed-ended questions have advantages: closed-ended questions are generally more straightforward and offer choices for respondents, closed questions guide respondents to specific information needed, closed questions permit to ask more questions in less 
time, and the data (answers) are easy to tabulate, and to analyze.

A total of 30 engineering students (13 females and 17 males) from Electrical Engineering Department at Khadoori University were involved in answering in the survey questions. The lab experiment is a circuit that can be configured either in series or in parallel, including electrical and electronic components and instrument such as resisters, power supply, and ammeters. This same experiment exists as hands-on, AR remote lab and virtual lab. Students carried out the same experiment (series and parallel circuit) using the hand-on lab, virtually using an electronic workbench program, and by using the implemented AR remote lab. After completing the three sessions, every student answered the prepared survey questions. The used survey questionnaire consisted of eight questions for evaluating the student perception of hand-on, virtual and AR remote labs, and five other general questions on the usage of the AR remote lab, using a five point, where scores of 1-5 were used to indicate levels of agreement with the statements. The results of the survey questionnaire are discussed in the following section.

After the students had finished the experiment on the three types of labs, they answered a list of common questions. The raw data is collected and analyzed. Fig. 2 displays a comparison of the labs regarding the students' perceptions and responses.

The analysis of the survey results gives these indicators:

1. Easy to use: The survey data indicates that while using the traditional lab, the students face some difficulties in the experimental work like wiring the circuit that must be isolated between wires in order to avoid any touch between them. In the virtual lab, the students need additional effort to learn how to use the software program of the virtual lab. In the AR remote lab, the design of the kit assists the students in the experimental work as all the components and instrument are presented on his screen. Thus, the students just need to wire the required components in the correct way to take the results from the screen through the Webcam.

2. Easy to understand the concept theory: As is obvious, the survey data of the three lab categories gives nearly the same degree in this question because all of these labs are established to demonstrate the theories, providing the students with additional skills of how to deal with these components and instruments in order to prove the concepts.

3. Available for enough time: The traditional lab is not available for enough time for that huge numbers of students to become familiarized with the electrical lab instruments and its components. On the contrary, virtual and AR remote labs are available for students. Using the virtual lab, which is a realized software program running on a $\mathrm{PC}$. In the case of the AR remote lab, the students interact with the AR remote lab from a terminal computer that is connected to the Internet. The students choose the experiment and its time through schedule time of the experiment to preserve their experimental time. An AR remote lab offers more enough time than traditional to enable more training and understanding of the problematic.

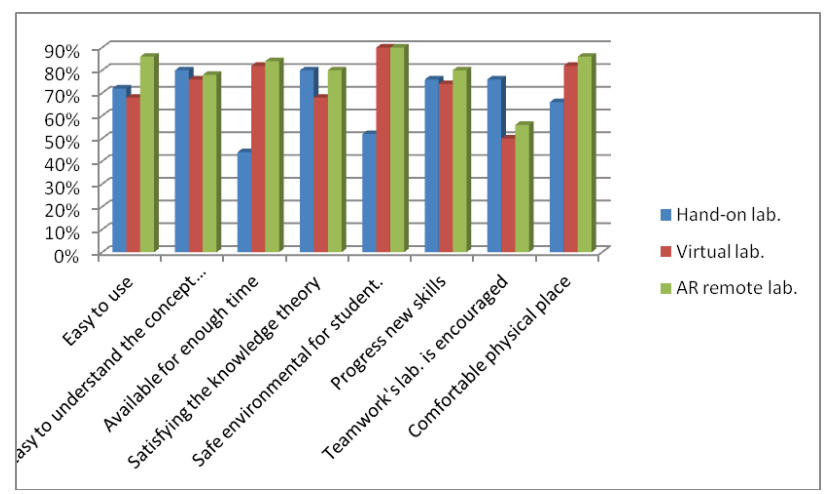

Figure 2. Survey results on hand-on, virtual, and AR remote labs.

4. Satisfying the knowledge theory: Carrying the experiment using the traditional and AR remote labs, the students deal with real components and instrument so they obtain real results in their environment of the lab. But in the virtual lab, students interact with a simulated experiment realized on a computer terminal and take the results from a mathematical model. In a simulated experiment, there are many errors that might occur and be ignored as: Tolerance errors from manufactories or surrounding temperature of components and instruments which causes some actual, traditional experiments not to properly work.

5. Safety environment: In the traditional lab, the students directly deal with electrical instrument, so the instructor must review the student's connections before executing their experiment, especially for high voltage connections which need more attention from students and instructor to avoid any critical error. These errors may harm the students or damage the instruments. In the virtual lab, the students deal with a mathematical model that represents a safe environment for the students; thus they are not afraid of any possible error. In the AR remote lab, the students work their experiment away from the electrical instrument, eliminating the students to be frightened from directly dealing with dangerous instruments. Furthermore, by using the implemented e-instructor in the AR remote lab, sensitive instruments and components are protected against damage. We can conclude that the AR remote lab offers a safe environment for both the students and instruments.

6. Progress new skills: The survey data shows almost equal results of these labs because of the fact that they are created to satisfy the electrical and electronic engineering theory through dealing with electrical components and instruments to prove concepts of new practical skills.

7. Team-work is encouraged: Team-work and communication skills can often be found in traditional labs. The virtual and AR remote labs, could discourage direct collaboration and communication skills. Further work is required in the design of AR remote labs to incorporate collaborative assignments and discussions that may enhance students' communication skills.

8. Comfortable physical place: The results indicated that the virtual and AR remote labs offer relaxed feeling while students perform their experiment from the computer at their specific times and away from electrical instruments. On the contrary, the traditional lab is not only restricted in time and place, but the stu- 
dents, instruments and instructors must be presented at the same place, causing uncomfortable feelings from tedious wiring and measurements that might damage the electrical instruments.

9. Experimental time: The required time for carrying out the experimental work for the same experiment in each lab was different. This is caused by the different environments of the three types of labs; In the traditional lab, the students, instruments and instructor must be at the same physical place; the experimental work needs instructor's supplement, which requires additional time, to verify the correctness of experimental connections, before feeding the circuit with power supply in order to avoid possible errors. In the virtual lab, the students take the experiment results directly from the mathematical model. During the experiment, the students just spend the time in choosing the components and connecting the virtually modeled circuit via a computer. In the AR remote lab, the students access their experiment through the Internet, and permitted to access the AR remote lab if they have a login name and a password to execute the experiment. It is undeniable that the bandwidth of the Internet influences the experimental time. For small Internet bandwidths, it is recommended to increase the time between two successive frames of the Web cam to avoid the delays due to the speed of transfer data via the Internet.

\section{CONCLUSION}

The results obtained from the comparative evaluation shows that the AR remote lab was generally well accepted. However, the feedback from the answers of the students indicated that they perceived AR remote lab as easy to use, easy to understand the concept theory, flexible to use in relation to time and place, safety environment and satisfying than virtual labs overall. AR remote lab is considered as synchronous interactive graphics system after recognizing and understanding the captured image of the experimental kit. The user can make the required connections using the interaction devices, keyboard and mouse. After validating these connections and changing the state of the relays that are responsible for the components connection by the server, measured data from the experiment is obtained from the instrument's screen through the Web camera, which transfers a live video stream of the real experiment to the remot computer screen of the students.

Students agreed that the AR remote lab experiment assists in illustrating learning concepts discussed at class. Furthermore, they feel that the AR remote lab is an effective system to enhance their knowledge and understanding of lectures. They are much more able to identify the inaccuracies and differences between experimental and theoretical results, as there is no simulation in AR remote lab, which means that AR remote lab environment is much alike the traditional labs. This can be achieved by overlaying real kits (stream video) with virtual (graphical) objects. Thus, the students are strongly immersed in their activity while carrying out experiments through AR remote lab.

\section{REFERENCES}

[1] Nedic, Z., Machotka, J., Nafalski, A.: Remote Laboratory NetLab for Effective Interaction with Real Equipment over the Internet. In: Proc. 2008 IEEE Conference on Human Systems Interaction (HSI),
Krakow, Poland, and pp.846-851, May http://dx.doi.org/10.1109/HSI.2008.4581553

[2] "Setting the Stage for a New Profession, Chemical Engineering in $1888, "$ www3.cems.umn.edu/orgs/aiche/archive/history/h 1888.html.

[3] Stephan, K., "All This and Engineering Too: A History of Accreditation Requirements," IEEE Technology and Society Magazine, Fall 2002, pp. 8-15. http://dx.doi.org/10.1109/MTAS.2002. 1035224

[4] Engineering Criteria 2000, Baltimore, Md.: ABET, 2002.

[5] Johnson, S.H., Luyben, W.L., and Talheim, D.L., "Undergraduate Interdisciplinary Controls Laboratory," Journal of Engineering Education, Vol. 84, No. 2, 1995, pp. 133-136. http://dx.doi.org/10.1002/j.2168-9830.1995.tb00160.x

[6] Flack, K., and Volino, R.J., "A Series-Parallel Heat Exchanger Experiment," Journal of Engineering Education, Vol. 88, No. 1, 1999, pp. 27-30. http://dx.doi.org/10.1002/j.2168-9830.1999. tb00407.x

[7] Bisantz, A.M., and Paquet, V.L., "Implementation and Evaluation of a Multi-course Case Study for Framing Laboratory Experiments," Journal of Engineering Education, Vol. 91, No. 3, 2002, pp. 299-307. http://dx.doi.org/10.1002/j.2168-9830.2002. tb00707.x

[8] Olinger, D.J., and Hermanson, J., "Integrated Thermal-Fluid Experiments in WPI's Discovery Classroom," Journal of Engineering Education, Vol. 91, No. 2, 2002, pp. 239-243. http://dx.doi.org/10.1002/j.2168-9830.2002.tb00697.x

[9] Okamura, A.M., Richard, C., and Cutkosky, M.R., "Feeling is Believing: Using a Force-Feedback Joystick to Teach Dynamic Systems," Journal of Engineering Education, Vol. 91, No. 3, 2002, pp. 345-349. http://dx.doi.org/10.1002/j.2168-9830.2002. tb00713.x

[10] Nippert, C., "Online Experiments-The Results of the Online Widener Laboratories," 32nd ASEE/IEEE Frontiers in Education Conference, Boston Mass., November 6-9, 2002, pp. T2E-12-T2E17.

[11] Feisel, L., and Peterson, G.D., "A Colloquy on Learning Objectives for Engineering Educational Laboratories," 2002 ASEE Annual Conference and Exposition, Montreal, Ontario, Canada, June $16-19,2002$.

[12] Peterson, G.D., and Feisel, L.D., "e-Learning: The Challenge for Engineering Education," e-Technologies in Engineering Education, A United Engineering Foundation Conference, Davos, Switzerland, 11-16 August, 2002, http://services.bepress.com/eci/etechnologies/.

[13] Bengiamin, N.Y., Johnson, A., Zidon, M., Moen, D., and Ludlow, D.K., "The Development of an Undergraduate Distance Learning Engineering Degree for Industry-A University/Industry Collaboration,"Journal of Engineering Education, Vol. 87, No. 3, 1998, pp. 277-282. http://dx.doi.org/10.1002/j.2168-9830.1998.tb00354.x

[14] Beston, W., Private Communication, April, 2004.

[15] Aleksandrova and N. Nancheva: "Electromagnetism-Interaction of Simulation and Real Lab Experiment", Information Technologies and Knowledge, Vol.1, 2007.

[16] S. Naidu: "E-Learning, A Guidebook of Principles, Procedures and Practices" (2nd edition), CEMCA, 2006.

[17] J. Ma And J. Nickerson: Hands-On, Simulated, and Remote Laboratories: A Comparative Literature Review. ACM Computer Survey , Vol.38, Issue 3, Article No.7, 2006.

[18] Nedic, Z., Machotka, J., Nafalski, A.: Remote laboratories versus virtual and real laboratories. In: Proc. of the 33rd ASEE/IEEE Frontiers in Education Conference, pp. T3E-1-6. Boulder, Colorado, USA, November (2003). http://dx.doi.org/10.1109/ fie. 2003.1263343

[19] E. Valentin, A. Verbraeck, and H. Sol: Advantages and Disadvantages of Building Blocks in Simulation Studies: Laboratory Experiment with Simulation Experts, Simulation in Industry 15th European Simulation Symposium, SCS-European Publishing House, 2003.

[20] B.Guimaraes, A. Souza, H. Gosmann, and A. Bauchspiess: "Internet Based Remote Laboratory: The Level Control of three coupled water Reservoirs", ACCA, Santiago de Chile, 2002. 
[21] N. A. Streitz: "Cognitive compatibility as a central issue in humancomputer interaction: Theoretical framework and empirical findings", Cognitive engineering in the design of human-computer interaction and expert systems, in G. Salvendy (Ed.), Amsterdam: Elsevier, pp. 75-82, 1987.

[22] Sommerville I. Software Engineering. Addison Wesley, 2007, pp. 68-69.

[23] Odeh, S., Abu Shanab, S. , Anabtawi, A., Hodrob, R. (2012). Remote Augmented Reality Engineering Labs. In: 2012 IEEE Global Engineering Education Conference (EDUCON), 17-20 April, Marrakesh, Morocco, pp. 955-960, ISBN: 978-1-1455-8. http://dx.doi.org/10.1109/EDUCON.2012.6201162

[24] Swan, J.E., Gabbard, J.L.: Survey of user-based experimentation in augmented reality. In: Proceedings of 1st International Conference on Virtual Reality (2005).

[25] Wang. X., Chen, I. R.: Usability Issues of an Augmented Virtuality Environment for Design. In: Lehmann-Grube, F., Sablatnig, J. (Eds.): FaVE 2009, LNICST 33, pp. 151-164 (2010).

[26] U. Reja, K. L. Manfreda, V. Hlebec, and V. Vehovar1: "Openended vs. Close-ended Questions in Web Questionnaires", Advances in Methodology and Statistics (Metodološki zvezki), 19, pp.159-177, 2003.

[27] Abu Shanab, S.,Odeh, S., Hodrob, R., Anabtawi, M. (2012). Augmented Reality Internet Labs Versus Hands-On and Virtual Labs: A Comparative Study. In: The 2012 International Conference on
Interactive Mobile and Computer Aided Learning (IMCL), 6-8 November, Amman, Jordan, pp. 17-21, ISBN: 978-1-4673-4924-6, (C)2012 IEEE. (IEEE Xplore). http://dx.doi.org/10.1109/ IMCL.2012.6396444

\section{AUTHORS}

Salaheddin Odeh is with the Department of Computer Engineering, Faculty of Engineering, Al-Quds University, Abu Dies, Jerusalem, Palestine (sodeh@eng.alquds.edu).

Shatha Abu Shanab is with the College of Engineering and Technology, Palestine Technical University-Kadoori, Tulkarm, Palestine (s.hodrob@ptuk.edu.ps).

Mahasen Anabtawi is with the Department of Computer Engineering, Faculty of Engineering, Al-Quds University, Abu Dies, Jerusalem, Palestine (manabtawi@eng.alquds.edu)

This paper presents an extended version of a paper entitled as "Augmented Reality Internet Labs Versus Hands-On and Virtual Labs: A Comparative Study" which was presented at The 2012 International Conference on Interactive Mobile and Computer Aided Learning (IMCL), 6-8 November, Amman, Jordan [27]. Submitted 24 December 2014. Published as resubmitted by the authors 11 May 2015 